\title{
PRÁTICAS ILÍCITAS, CORRUPTELAS E VENALIDADE NO ESTADO DO BRASIL A INÍCIOS DO SÉCULO XVII. O fracasso das tentativas de reforma de Filipe III para o Brasil $^{1}$
}

\author{
José Manuel Santos Pérez*
}

\begin{abstract}
RESUMO: A questão da venalidade é pouco conhecida para o território da América portuguesa no período da união de coroas ibéricas, entre 1580 e 1640. Novos documentos, encontrados em arquivos na Espanha, como o Arquivo General de Simancas e a Biblioteca Nacional de Madri, oferecem interessantes informações sobre as tentativas de reforma durante o reinado de Filipe III (II de Portugal), a compra-venda de cargos, as formas de provimento dos ofícios e as suspeitas de "corruptelas" nas práticas dos oficiais régios.

PALAVRAS-CHAVE: Corrupção; Venalidade; Provimento de cargos; União Ibérica.
\end{abstract}

\section{Illegal practices, corruption and venality in the State of Brazil at the beginning of the 17th century. The failure of Filipe III's attempts to reform Brazil}

ABSTRACT: The sale of public offices is a question little known in the territory of Portuguese America in times of the Iberian Union, between 1580 and 1640. New documents, found in Spanish archives, such as the Archivo General de Simancas and the Biblioteca Nacional in Madrid, give us interesting information about the plans of reform during the reign of Philip III (II of Portugal), sale of offices, ways of appointment of officers, and suspicion of corruption in the practices of royal agents.

KEYWORDS: Corruption; Sale of public offices; Appointment of officers, Iberian Union.

\section{Prácticas ilícitas, corruptelas y venalidad en el Estado de Brasil a inicios del siglo XVII. EI fracaso de los intentos de reforma de Filipe III para Brasil}

RESUMEN: La cuestión de la venalidade es poco conocida para el território de la América portuguesa em el período de la unión de coronas ibéricas, entre 1580 y 1640. Nuevos documentos, encontrados en archivos en España, como el Archivo General de Simancas y la Biblioteca Nacional de Madrid, ofrecen interesantes informaciones sobre las tentativas de reforma durante el reinado de Felipe III (II de Portugal), la compra-venta de cargos, las formas de acceso a los ofícios y las sospechas de "corruptelas" en las prácticas de los oficiales regios.

PALABRAS CLAVE: Corrupción; Venalidade; Acceso a cargos y ofícios; Unión Ibérica.

\footnotetext{
* Doutor em História. Professor Titular de História da América no Departamento de Historia Medieval, Moderna y Contemporánea. Facultad de Geografía e Historia da Universidade de Salamanca. Contato: Universidade de Salamanca, Calle Cervantes s/n, 37002, Salamanca, Espanha. E-mail: manuel@usal.es, ORCID: http://orcid.org/0000-0002-8684-9798.
} 
A Biblioteca Nacional da Espanha em Madri possui preciosos manuscritos relacionados com a América portuguesa. Dentre eles há um que não tem suscitado muito interesse por parte dos historiadores, mas que oferece informações muito interessantes sobre a questão da "corrupção", das más práticas ou mau governo, como às vezes eram identificadas tais práticas nos documentos da época. É possível que este documento seja um dos primeiros em que se usa, no Brasil, a palavra "corruptela" para designar um comportamento desviado por parte dos agentes da coroa destacados no território. O documento tem por título "Relaçao de todos os oficios da fazenda e justisa que ha neste Estado do Brazil, e quaes pertencen ao provimento de V. Mag. e aos dos donatarios em vida, ou por tempo limitado, para cuja inteligencia se hao de supor os premissos segintes: ${ }^{2}$ "

Trata-se de um relatório enviado ao Rei pelo governador geral do Brasil à época, com informações sobre os ofícios do Estado do Brasil, a forma do seu provimento, as diferenças entre os que estão em capitanias de donatário e os que estão em capitanias reais, os "ordenados e percalços" ${ }^{3 "}$ de cada ofício, além de outras informações. O documento não tem data. Guida Marques o datou de 1615 , mas não parece ser desse $a o^{4}$. O governador geral nessa altura era Gaspar de Sousa, mas o documento cita este personagem, de modo que ele não pode ser o autor. Comentários sobre a "recente conquista" do Maranhão e a falta de uma estrutura administrativa desse território, nos levam a pensar que o autor é o sucessor de Gaspar, Luís de Sousa, governador entre 1617 e 1621. Portanto podemos datar o documento em c.1618. A segunda parte do relatório, a mais longa, é uma relação de todos os ofícios, ordenada por capitanias, com seus ordenados e os percalços que podiam receber. $\mathrm{O}$ autor, na introdução, expõe uns "premissos" que, segundo ele, deveriam ser cumpridos para não ir contra a lei no que respeitava ao provimento dos cargos e a maneira como os agentes da administração realizavam suas funções. Os dois primeiros "premissos" indicavam que todos os ofícios de fazenda do Brasil, inclusive nas capitanias de donatário, eram de provisão real (ou dos governadores gerais em seu nome). Os cargos de justiça "em vida" eram de provimento dos donatários, enquanto que as serventias desses mesmos cargos eram de competência do Rei. Advertia também que todos esses cargos eram de "propriedade", ou seja, vitalícios, sem terem um tempo limitado. Apenas quando falecia um proprietário, durante o tempo em que se esperava pela chegada do seguinte, El-Rey ou o governador o proviam de maneira provisória, segundo lembrava o governador. O mais interessante dos "premissos" é o quarto, que citamos por completo: 


\begin{abstract}
"Que a mayor parte dos precalços que levao os oficiais sao introduzidos por eles mesmos sem provisao ou regimento de V. Mgd.; e assim cada pessoa que novamente vem provida na propriedade dos taes officios os acrecentao como the paresse, ao que V. Mgd deve mandar acudir porque posto que eu tratei de o remedear se pegao ao costume ou para melhor dizer corruptela, e assyn nao pude alterar o estado em que achey as cousas neste particular sem expressa ordem de V. Mge."
\end{abstract}

O governador mostrava-se também preocupado porque havia muitas queixas sobre o excesso dos ordenados e dos percalços dos oficiais da fazenda e da justiça. Segundo ele, isso se devia ao fato de muitos desses cargos não estarem providos em propriedade, o que evitava fixar um limite aos ordenados através do regimento. Do total de 258 cargos descritos pelo governador nas 11 capitanias do Estado do Brasil, o documento informa que 40 estavam em situação de serventia e 40 em propriedade. Sobre o resto não aponta detalhes.

No quinto "premisso" consta que essas queixas obrigaram o Rei a mandar ao governador Diogo de Menezes um regimento com os salários e percalços que deviam receber. O tal regimento foi feito por Gaspar de Sousa na Bahia, e foi enviado ao "Conselho do Paço", mas não se obteve resposta.

O que este documento reflete é um cenário de descontrole em várias questões relacionadas aos cargos administrativos que estava ocorrendo no território do Estado do Brasil nos anos iniciais do século XVII. A burocracia real estava crescendo de maneira importante. Se o documento de c.1618 faz menção a 258 cargos, um documento datado de 1606 e enviado pelo governador do Brasil, Diogo Botelho, intitulado "Relaçao dos officios dapresentaçao de S. Magde da Justiça e Fazenda e o que valem de renda e de compra”, reúne até 102 cargos diferentes de provimento real. Muitos desses ofícios tinham um valor de compra e quase todos gozavam dos tais "percalços" que complementavam o ordenado ou salário designado. Os "percalços", tal como são descritos pelo governador Luís de Sousa, eram claramente uma fonte de práticas corruptas. Cada um dos cargos tinha a possibilidade de ingressar um dinheiro "extra", por fora do ordenado, através de algumas das atividades relacionadas com o ofício nas capitanias que tinham comércio ultramarino.

Por exemplo, o Provedor da Fazenda de Pernambuco poderia receber do despacho de cada navio 320 réis; de cada pessoa que levava cargas nos navios uns 120 réis por ano; 40 réis por cada selo que punham nas certidões; 30 réis por cada peça de escravo, o que lhe rendia 100.000 réis por ano; 4 réis de cada quintal de pau brasil por conta dos contratadores, o que lhe atribuía 40.000 réis por ano; pela arrematação do contrato dos dízimos recebia a cada ano 100.000 réis, que podia ser mais segundo a vontade do contratador; de cada engenho 
reformado mais 20.000 réis. Esse oficial tinha um ordenado de 350.000 réis por ano, o que junto com os percalços podia representar uma importante quantidade anual ${ }^{7}$. Comparando os percalços de 1606 e c.1618, com esses dois documentos como base, podemos comprovar como em algumas partidas, como o cobrado por cada "peça" de escravos, o rendimento cresceu de maneira notável durante o período, passando em alguns casos de 40.000 a 140.000 réis por ano.

Segundo diferentes informações, o salário dos oficiais, isto é, o seu ordenado, era pago com $2 \%$ do valor do contrato dos dízimos de cada capitania, havendo assim uma relação muito estreita entre os arrendadores dos contratos, normalmente grandes comerciantes cristãos-novos, ou agentes de casas comerciantes de Lisboa, e os oficiais régios, que dependiam daqueles para seu sustento.

O provedor mor da fazenda do Brasil, Ambrósio Siqueira, enviou em 1605 ao Rei uma Relação de gastos coloniais. Nela afirmava que "os ordenados da Fazenda de Vossa Majestade nesta Capitania dos oficiais dela tem todos a $2 \%$ de tudo o que vier à receita do Almoxarife dela e se puser em arrecadação por conta da Fazenda de Vossa Majestade..."8. Esses $2 \%$ eram, porém, sobre o que rendia a fazenda na capitania na qual estava o oficial. $\mathrm{O}$ provedor da fazenda de Pernambuco, Miguel Gonçalvez, por exemplo, recebeu o cargo de propriedade "em sua vida" por provimento real de D. Sebastião em 1577, "com ordenado de $2 \%$ de tudo o que viesse e se pusesse em arrecadação da Fazenda de Vossa Majestade na receita do Almoxarife dela" ${ }^{9}$. A prática continuava em 1618, segundo o descrito pelo governador Sousa, com vários cargos recebendo 3 ou 2 por cento da arrecadação, como o escrivão da câmara de Olinda, a quem era designado até 150.000 réis dessa maneira, o provedor da fazenda e o almoxarife de Ilhéus, ou o almoxarife e o escrivão da fazenda de Porto Seguro. Isso ocorria apesar do que o governador Luís de Sousa comentava que o Rei tinha passado uma provisão para que os oficiais da fazenda de todo o Estado do Brasil não recebessem esses tantos por cento, que em algumas capitanias, como Itamaracá, havia sido substituído por um pagamento anual segundo aparecia na folha geral do assentamento que os governadores obtinham ao serem nomeados.

No documento da Biblioteca Nacional de Madri interessa salientar o uso da palavra "corruptela" no quarto "premisso". O governador a usa para definir "o costume" dos oficiais de atribuírem, segundo a vontade deles, os percalços que recebiam com as atividades do cargo. Mas também devia querer definir essa prática de as pessoas abusarem do cargo durante o tempo que o tinham em serventia, o que devia ser muito comum e era motivo de queixas. 
Devemos, portanto, destacar a importância deste documento, porquanto apresenta uma situação que os contemporâneos definiam como "corruptela", o que não é muito comum na época, e situá-lo no contexto da discussão historiográfica sobre a "corrupção" ou as práticas corruptas no período colonial.

A questão da corrupção não tem tido a mesma centralidade na historiografia sobre a América portuguesa que já teve no caso da América espanhola. Como lembra Adriana Romeiro, em recente e excelente estudo publicado sobre esta questão: “a corrupção ainda não foi objeto de investigação sistemática por parte dos historiadores da época colonial brasileira" ${ }^{10}$. Em estudo clássico, Horst Pietschmann, seguindo autores como Leddy Phelan, van Klaveren e Vicens Vives, situou a corrupção, na América hispânica, no centro da realidade colonial, e a considerou "estrutural", formando parte do sistema. O termo, segundo o autor alemão, teria algo de "anacrônico" já que nas colônias existiria uma "moralidade" diferente, condicionada pela dinâmica dos diferentes grupos sociais. Por detrás dessas práticas “corruptas" estaria, segundo Pietschmann, a expressão de uma tensão entre a coroa e os particulares pela distribuição de poder e riqueza. Segundo o autor alemão a realidade colonial hispânica tinha dois aspectos que faziam inevitáveis, e, portanto, sistêmicas, as práticas corruptas: a venda de cargos e o contrabando ${ }^{11}$.

Em publicação recente, os historiadores espanhóis Pilar Ponce Leiva e Francisco Andújar Castillo defendem a existência de três grandes linhas interpretativas sobre o fenómeno da corrupção: uma primeira analisa o passado aplicando a categoria de "corrupção" sem questionar se as práticas ilícitas eram ou não interpretadas como corruptas na época estudada; uma segunda opta por não usar o termo "corrupção" ou fazê-lo de uma maneira moderada, não indiscriminada, para muitas práticas que tanto ontem como hoje estão atreladas ao termo "corrupção", como suborno, desfalques ou outros termos parecidos; e finalmente uma terceira, "funcionalista", que interpreta que a "corrupção" possuía uma "função" na realidade política, econômica e social, que "lubrificava" o sistema e permitia partilhar poder e riqueza sem chegar ao conflito violento ${ }^{12}$.

Devemos indicar que essas últimas interpretações "funcionalistas", que preferiam não falar de "corrupção" por ser um elemento "estrutural", estão sendo superadas na atualidade por visões que encontram, sim, uma censura da corrupção e dos "excessos" dos oficiais e burocratas na época moderna, e põem o enfoque nos numerosos sistemas de contenção e fiscalização criados por essas estruturas "proto-estatais" para evitar que as práticas corruptas se generalizaram. 
Como mencionado, a questão não tem despertado o mesmo interesse nos estudos sobre a América portuguesa. Apenas Boxer, Raymundo Faoro, Fernando Novais e mais recentemente Laura de Mello de Souza, trataram de práticas corruptas ligadas ao contrabando, fundamentalmente, e constitutivas de um spoil system, onde os oficiais régios podiam enriquecer-se por meios lícitos e ilícitos, contanto que, com essa riqueza, atendessem também às necessidades da coroa. Adriana Romeiro, que sistematiza a historiografia existente sobre a América portuguesa, destaca a influência de Antônio Manuel Hespanha nas últimas contribuições da historiografia brasileira e lembra que, para o autor português, o termo "corrupção" seria um anacronismo, pois os oficiais régios gozavam de uma autonomia que não contrariava a lei, um "espaço de poder autônomo efetivo" onde situa "o sistemático incumprimento ou descaso da lei... o contrabando generalizado, os abusos e usurpação dos poderes dos locais, etc ${ }^{13}$ ". Da influência de Hespanha derivaria, segundo Romeiro, a excessiva centralidade do sistema de mercês, ou economia do dom, na análise sobre a realidade política social da colônia, subestimando assim o "atrativo das vantagens financeiras situadas fora" do espaço das mercês ${ }^{14}$. Romeiro finalmente defende um enfoque mais cultural para o estudo das práticas ilícitas, e pede para que se supere a ideia de um homo economicus, já que "não só os homens agem sempre de acordo com uma racionalidade, ... o imaginário dos homens da Época Moderna [estava] orientado pelos afetos e pelas paixões"15.

O documento citado ao início entra plenamente nesta discussão. Não apenas temos um documento que refere explicitamente a "corruptelas", raro na época, mas que alude a essas práticas no contexto do provimento de cargos da fazenda e da justiça na América portuguesa, um tema que a historiografia sobre o período da união de coroas ibéricas (1580-1640), parece ter esquecido. Não temos nem de longe tanta tradição de estudos da venalidade na América portuguesa como temos para a América espanhola. Inclusive, Romeiro parece dar menos importância a esta questão na análise já citada. No território espanhol na América, este assunto se demonstrou fundamental, já que por meio da compra e venda dos cargos, a maioria deles comprados por elites locais, o exercício e a articulação do poder ultramarino esteve, no período que vai de 1600 até meados do século XVIII, nas mãos destes grupos de "criollos" ou de pessoas com fortes vínculos com as famílias notáveis do território americano. Estes grupos aproveitaram bem suas redes e sua penetração nas estruturas administrativas do império de ultramar para consolidar suas hegemonias econômicas e sociais e conseguir benefícios a través das decisões políticas régias, sobre as quais às vezes influenciavam de maneira fundamental. Na lógica dos "Impérios negociados", interpretação historiográfica de maior 
aceitação, essas elites ocupavam bases sólidas de poder e tinham uma importante capacidade para negociar com o centro político. Mediante muitos estudos realizados nos últimos 30 anos, a historiografia sobre a América hispânica tem identificado duas grandes questões que seriam fundamentais para se entender o império espanhol: a utilização de cargos da monarquia por parte das elites coloniais, por meio da venalidade, e a organização social em redes, com uma base familiar, que uniam setores muito diversos dessa realidade social americana colonial ${ }^{16}$.

Para o caso da América portuguesa, apenas contamos com alguns estudos importantes sobre venalidade para o século XVIII, fundamentalmente para o período a partir da legalização das vendas em $1741^{17}$. Da leitura desses estudos podemos concluir que a venalidade teve caráter excepcional nos territórios da monarquia portuguesa. As vendas de cargos não teriam sido muito numerosas nem generalizadas, o que seria causado pelo interesse régio na seleção cuidadosa do pessoal burocrático. As vendas existiriam, mas seriam poucas, e nunca chegaram a atingir a importância que sabemos que tiveram nos territórios hispânicos. É só a partir de 1741 que a coroa portuguesa deu licença para as vendas e compras, com muitas restrições, e com finalidade política mais que econômica, relacionada com a necessidade de manter sob controle e de maneira centralizada o sistema burocrático, visando a uma maior fiscalização das vendas privadas de cargos entre particulares. Esta medida lembra muito à que tomou Felipe II em 1591 nos territórios hispânicos, quando permitiu a venda de cargos sem poder judicial, fundamentalmente os postos de regidor (vereador) e escrivão, precisamente para controlar a prática muito comum das vendas entre particulares.

Haveria, portanto, uma excepcionalidade portuguesa sobre venalidade no Antigo Regime? Alguns autores afirmam que sim, e acrescentam ainda que a extensão da venalidade e os benefícios obtidos por meio dela pela monarquia lusa estariam muito longe do que aconteceu com as monarquias espanhola e francesa no mesmo período. Se a coroa portuguesa foi mais prudente com as vendas de cargos, a pergunta é por que isto foi assim. Algumas das razões apontadas pelos diferentes autores seriam que houve uma menor necessidade de financiamento, por menos intervenção em guerras; ou que a venalidade poderia afetar à “justiça redistributiva”, uma vez que diminuiria a quantidade de "prêmios" que podiam ser outorgados, enfraquecendo assim a reciprocidade entre Rei e vassalos. Os debates sobre a venda de cargos foram muito intensos no período pós-Restauração, quando a propaganda bragantina acusava as autoridades espanholas de terem vendido tantos ofícios que a monarquia parecia um "leilão de cargos" ". Naquele período, segundo alguns predicadores, se 
vendiam "com tendas abertas, e publicamente, ... os cargos, os bispados, as comendas, os títulos, e toda a maneira de cargos, ofícios e dignidades"19.

Esses argumentos se assemelham mais à propaganda que à realidade, mas a questão importante é que vários historiadores, sejam portugueses ou brasileiros, parecem aceitar essa "superabundância" das vendas durante o período habsbúrguico, em comparação com o período bragantino posterior. Apenas o historiador Francisco Silva chamou a atenção para uma generalização da venda de cargos prévia ao período da união das coroas ibéricas. Segundo este autor, é muito provável que "todos os ofícios da fazenda do Porto tivessem sido tocados pela venalidade a meados do século XVI"20. A compra-venda de cargos seria assim comum antes, durante e depois do domínio habsbúrguico. Silva argumenta, ainda, longe de ser um período de grande aumento da venalidade, houve importantes restrições a estas práticas que foram reforçadas durante este período. Temos vários exemplos: a partir de 1620, o Rei condicionou as serventias por impedimento do proprietário à informação prévia sobre as causas do impedimento e sobre o rendimento do ofício. Em 1629, uma "Junta" reunida em Madri, com o propósito de conseguir um rendimento maior da fazenda portuguesa, chegou à conclusão que não deviam vender-se cargos da Fazenda e da Justiça, pois dessa maneira entrariam na administração os "ricos e não aptos" fechando a porta aos "bons e aptos",21. A partir de 1636, o Rei exigiu que o pedido de renúncia em favor de um filho fosse acompanhado da informação sobre quanto tempo o solicitante exerceu o cargo. Também condicionava o Rei a hereditariedade dos cargos a um exame prévio de idoneidade do sucessor. Por fim, durante os reinados de Filipe III e Filipe IV publicaram-se portarias e cartas régias que proibiam as renúncias que não fossem de pais para filhos. A conclusão mais provável, como já afirmou Silva é que, apesar das restrições, as vendas de cargos ocorreram "por todo o Reino... e continuaram pelos séculos... até a sua proibição definitiva em 1770" 22 .

Os documentos que citamos ao início deste artigo parecem provar a ideia do autor português. Por um lado, descortinam uma realidade de vendas privadas de cargos muito generalizada na América portuguesa. Por outro, concordam com a ideia de uma burocracia autônoma que inclusive decidia quais eram os salários e ingressos econômicos que deviam ter por sua atividade burocrática. Os ingressos chegavam pela via do ordenado e dos "prós e percalços". Estes últimos não eram práticas ilícitas. O que fazia deles "ilícitos" era o abuso que os oficiais faziam com eles. O ordenado, porém, era 2 ou 3\% do arrecadado em cada capitania pelos contratadores dos impostos. Como já mencionado, tal arrecadação envolvia uma relação estreita entre as casas comerciantes, normalmente de cristãos-novos, e a 
burocracia colonial. A patrimonialização dos cargos estava também no centro destas práticas consideradas “corruptelas" pelo governador no documento da Biblioteca Nacional de Madri. A hereditariedade dos ofícios continha algumas restrições, mas isso não impediu um usufruto do cargo como se fosse um bem patrimonial. O cargo podia ser usado como dote de casamento, transmissível por intermédio de uma filha ou de uma viúva. Os proprietários podiam também arrendar o usufruto dos ofícios, fazer renúncias, com licença real, vender o ofício ou penhorar os rendimentos, como pagamento de dívidas. Normalmente os arrendatários deviam pagar um terço do rendimento anual dos ofícios ao proprietário ${ }^{23}$. Ao que parece, patrimonialização dos cargos estava muito estendida nas conquistas do Estado da Índia, nas possessões africanas e nos Estados do Brasil e do Maranhão durante toda a Idade Moderna $^{24}$.

Para entender melhor o que estava acontecendo com a venalidade na América portuguesa, achamos que devemos analisar algumas questões: primeiro, se a situação econômica global e a particular do Estado do Brasil fazia desnecessário o mercado de ofícios; segundo, se a pratica generalizada da venalidade na monarquia hispânica e em seus territórios americanos "contagiou" os territórios portugueses; e terceiro, se houve mudanças importantes no sistema de acesso aos cargos durante o período em que Portugal ficou sob o poder dos Habsburgo e, se isso ocorreu, que consequências teve diante da resistência portuguesa a práticas consideradas "imorais".

Sobre a primeira questão, o argumento econômico, achamos que seria excessivo fazer uma relação direta entre a venda de cargos e a situação econômica do Reino de Portugal a suas possessões ultramarinas no conjunto da monarquia hispânica. É muito difícil quantificar o que significou a entrada de Portugal na monarquia dos Habsburgo. É indubitável que constituiu um importante aporte financeiro, mas também que acarretou um aumento dos gastos de defesa. Para a monarquia, o que contava não era a performance de um ou outro território, mas o balanço total. Nas palavras de Carlos Marichal: "a dinâmica fiscal do Estado imperial espanhol correspondia a complexos fluxos de fundos no âmbito intra-imperial, seja entre colônias e metrópole, como entre as próprias colônias hispano-americanas" 25 . O aporte do Brasil às finanças reais a inícios do século XVII era de pouco mais de 4,7 \% do total arrecadado, mas é muito possível que as receitas obtidas nesse território cresceram ao longo das primeiras décadas do século. No entanto, também cresceram os gastos: em momentos como a conquista do Maranhão, ou depois da invasão holandesa de Salvador, as despesas aumentaram enormemente. Do Brasil a coroa recebia aproximadamente 206.000 pesos (um 
peso: 320 réis) enquanto o gasto era de uns 132.000 pesos. Esta situação de superávit de 1607, foi mudando ao longo do século, e muito claramente depois de 1624, quando o gasto militar cresceu e obrigou a criar novos impostos como o do sal ou o do vinho ${ }^{26}$. Como já apontou Ângelo Carrara, é complicado quantificar o que significou a entrada do Brasil no império dos Habsburgo em termos econômicos. O assunto preocupou muito os burocratas de Filipe III, os quais pediram numerosos relatórios sobre a situação financeira da maior das possessões portuguesas no Atlântico. Um dos documentos mais importantes enviados desde o Brasil à corte, foi a mencionada anteriormente "Relação da receita e despesa do Estado do Brasil" de 1605, do provedor da fazenda Ambrósio de Siqueira. Houve outras "Relações" sobre a situação econômica da América portuguesa entre 1608 e 1610, como a "Relação das capitanias do Brasil", provavelmente de $1607^{27}$, junto com os documentos de 1606 e de c.1618, aqui analisados. A razão de pedir tantas informações sobre o estado financeiro do Estado do Brasil provavelmente tinha a ver com uma suspeita de que a realidade econômica desse território era muito melhor do que mostrava a arrecadação de impostos. As autoridades em Madrid deviam pensar que o Brasil poderia render mais, tanto por sua proximidade às ricas possessões da América hispânica quanto pelo dinamismo econômico mostrado pela indústria do açúcar. Além disso, nas primeiras duas décadas do século XVII, chegaram na Espanha muitos testemunhos sobre existência de metais preciosos na região, especificamente nos relatos de Gabriel Soares de Sousa ou Francisco de Sousa. Tal fato despertou também o interesse régio.

A segunda questão das apontadas anteriormente, sobre se houve ou não "um contágio" entre as "práticas castelhanas" e as práticas das conquistas portuguesas no Atlântico durante o período de inícios do século XVII, nos leva a outras digressões. O documento enviado por Diogo Botelho em 1606 com o título ""Relaçao dos officios dapresentaçao de S. Magde da Justiça e Fazenda e o que valem de renda e de compra" ${ }^{28}$, nos oferece uma informação completa sobre a situação do sistema burocrático do território português ao início do século XVII. Os dados que apresenta o documento dão uma ideia do que estava acontecendo com muitos cargos (menores) no território do Estado do Brasil a inícios do século XVII: aparece uma lista de todos os ofícios do Brasil com o "ordenado", o valor de compra e os "percalços" que esperavam obter pelas suas atividades. Durante o ano de 1606 Botelho enviou várias cartas ao vice-rei de Portugal e ao Conselho da Índia pedindo esclarecimentos sobre o ordenado, que, como mencionado anteriormente, às vezes era uma quantidade fixa, mas outras, uma porcentagem da quantidade que um contratador pagava à coroa pelo 
arrendamento da arrecadação dos impostos (fundamentalmente o dízimo do açúcar) em cada uma das capitanias. Sabemos que pouco tempo antes da redação do documento as autoridades de Madri estavam ordenando que se acabasse essa prática do pagamento em tantos por cento, e que alguns dos cargos fossem suprimidos, talvez porque pensavam que de fato existiam abusos. É nesta lógica de requerimentos contínuos por parte de Madri, que o governador e o provedor das contas enviaram esse exaustivo estudo com a situação dos ofícios em todas as capitanias do Estado do Brasil com data de 2 de outubro de 1606, o qual chegou ao Conselho da Índia em 24 de abril de 1607. O documento foi enviado em duas cópias com 6 folhas, dando a informação completa sobre ordenados, percalços e o valor de compra dos cargos das capitanias portuguesas. O preço do ofício variava conforme a compra fosse para o cargo "em vida", ou seja, em propriedade, ou não, e também segundo as quantidades que se esperava receber por meio dos "percalços". O ofício mais caro era o do escrivão da fazenda da Baia, que tinha um valor de um conto e dez mil réis. Outros ofícios dessa capitania se vendiam por um conto de réis. $\mathrm{O}$ de menor preço era de 1.000 réis, pagos por um cargo de meirinho do $\operatorname{mar}^{29}$. Os ofícios "maiores" como capitão ou ouvidor geral parecem estar fora do "mercado", e no documento se menciona o seguinte sobre eles: "Os ofícios de iulgar que tem alçada por Sua Magestade não tem avaliação".

Apesar das similitudes com as práticas da venalidade nos territórios espanhóis na América, este documento da Biblioteca da Ajuda não demostra um "contágio", nem uma cultura generalizada de vendas de cargos por parte da coroa. O que parece mostrar é uma prática muito comum de vendas de cargos entre particulares, a qual estava começando a ter uma vigilância maior por parte das autoridades, provavelmente para tirar proveito também dessas vendas fora do sistema oficial. O mesmo aconteceu na América hispânica em 1591, quando Filipe II legalizou a venda dos cargos de regidor e de escrivão nos territórios de ultramar. As autoridades régias queriam, com essa nova norma, regular umas vendas que escapavam do controle oficial e ganhar um rendimento por cargos que, conforme à lei, eram propriedade do Rei e somente ele ou os burocratas designados por ele podiam outorgá-los. Podemos pensar, portanto, que os homens de Filipe III, na altura de 1606, estavam tentando organizar um melhor controle dessas vendas de cargos entre particulares na América portuguesa. Quase ao mesmo tempo, na América hispânica, Filipe III promulgava a "Real Cédula" de 14 de dezembro de 1606 pela qual era permitido aos proprietários dos ofícios nas Índias, prévio pagamento, fazer renunciação dos mesmos e transmiti-los a outros. Esta prática 
de renúncia devia também estar sendo comum entre particulares, e a coroa começava assim a fazer um maior controle da prática.

Estas medidas de regulação das vendas formavam parte de um intenso "pacote reformista" para a América portuguesa dos primeiros anos do governo de Filipe III. Esse "pacote" incluía, ademais dessa regulação da venalidade, uma maior vigilância sobre as contas da estrutura administrativa e o envio ao Brasil de "visitadores" como Sebastião Carvalho, para investigar sobre os abusos com o comércio do pau-brasil ${ }^{30}$. Esse interesse da coroa pelos assuntos "brasileiros" continuou uns anos depois: em 1618 o vice-rei de Portugal recebeu o pedido de uma "Relação de todos os ofícios da justiça, fazenda e guerra" que havia no Estado do Brasil e Angola, indicando quais eram de propriedade e quais eram por tempo limitado, incluindo também os que estiveram vacantes ${ }^{31}$. Provavelmente este é o pedido que originou o documento apresentado ao início. Esse pedido faz parte de um grande projeto da Monarquia hispânica para o território do Maranhão depois de sua conquista em 1615: ordenou-se a divisão do território da América portuguesa nos dois estados, do Maranhão e do Brasil; fez-se um pedido aos franciscanos para empreender a conquista das almas (evitando assim a presença da onipresente ordem dos jesuítas); mandou-se fazer um plano de repovoamento do território; e foi nomeado o primeiro governador para a região, o espanhol Diego de Cárcamo, que finalmente morreria antes de ocupar o cargo ${ }^{32}$. Em um momento de forte estresse para o sistema financeiro régio na América portuguesa (durante este período os gastos militares cresceram enormemente) a coroa quis saber o custo do sistema burocrático e, talvez, utilizar a venda de cargos como uma fonte suplementar de ingressos.

Passemos a considerar a terceira questão, se houve ou não transformações no procedimento de provisão de cargos nos momentos iniciais do século XVII. Podemos dizer a respeito que a tensão reformista do período se chocava com a realidade. O desenvolvimento de um procedimento mais regulado e controlado desde o centro para o provimento de cargos nas conquistas teve muitos obstáculos. Não apenas a existência de uma prática estendida no Brasil de vendas particulares de cargos, mas também as muitas contradições de uma política monárquica errática e desorganizada, junto com os numerosos confrontos dentro do sistema conciliar, especialmente nos Conselhos de Portugal e da Fazenda, onde nem sempre eram aceitas as ordens régias.

A política reformista para os territórios portugueses do Atlântico dos primeiros anos do reinado de Felipe III ostentava vários objetivos: a fazenda queria uma avaliação de todo o sistema, para efetuar mudanças que tivessem como alvo uma melhor arrecadação, apostando 
também por um apoio a projetos que visavam encontrar minas de prata e ouro na região; na parte de guerra, o sistema hispano-luso ideou uma maior presença naval no Atlântico que devia ir acompanhada de um reforço da defesa do litoral, o qual devia ser feito com um esforço misto, tanto da coroa como dos locais; para tanto, se incentivou a construção de fortalezas que deviam ser financiadas com novos impostos, fundamentalmente sobre o vinho e o sal, pagos pela população urbana local; no que se refere à justiça, devia ser implementada uma nova estrutura, com centro na Relação da Bahia, para fiscalizar todo o sistema, reforçando também outros sistemas de controle como as visitas e os juízos de residência ao final dos mandatos dos oficiais. Para tanto era fundamental também organizar um sistema mais fiável de provimento de cargos, mais eficaz e adequado às novas circunstâncias. Tudo devia ser feito sem alterar excessivamente o sistema português, respeitando a autonomia e o princípio de que apenas pessoas nascidas em Portugal deviam ocupar os ofícios nas conquistas. Como demonstra o Banco de dados Brasilhis, que já identificou mais de 1.000 pessoas com cargos nos Estados do Brasil e do Maranhão no período de 1580 a 1640, este princípio foi respeitado, pois quase não há exceções a essa norma geral ${ }^{33}$.

Durante o período habsbúrguico continuaram praticamente os mesmos procedimentos que eram normais na Coroa portuguesa para o provimento de cargos: a pessoa interessada num ofício fazia uma solicitação às autoridades, normalmente ao vice-rei de Lisboa, quando o cargo estivesse vacante. O vice-rei enviava o pedido ao Conselho da Fazenda (ou ao Conselho da Índia até o seu desaparecimento em 1614) junto com informes que testemunhavam a "qualidade" do solicitante e o bom desempenho em ofícios anteriores. A decisão do Conselho era enviada posteriormente ao Rei para a sua confirmação. Às vezes uma pessoa podia solicitar um cargo para outra, como foi o caso do bispo e capelão-mor Jorge de Ataíde a quem o rei tinha concedido um alvará de lembrança para quatro serventes quando houvesse algum cargo livre. Dois desses serventes tiveram cargos: Sebastião Borges, escrivão da câmara do Porto, foi nomeado provedor da fazenda do Estado do Brasil, e Gabriel Correia de Bulhões recebeu o cargo de almoxarife da capitania de Pernambuco ${ }^{34}$.

A partir de 1605, as autoridades portuguesas começaram a receber ordens para mudar alguns aspectos do sistema burocrático das conquistas. O Rei pediu ao provedor Siqueira enviar toda a informação disponível sobre os cargos, ordenou ao vice-rei mandar informação sobre o ordenado do escrivão da fazenda e contador da Bahia, e no dia 13 de outubro proibiu que os ofícios das partes do Brasil recebessem aqueles 1, 2 ou 3 por cento que recebiam dos contratadores, e que se fixasse um ordenado para cada um deles ${ }^{35}$. Também foi decretado que 
os ofícios da Fazenda não se servissem em propriedade e que os nomeados ocupassem o cargo por 3 ou, no máximo, 5 anos, tendo que fazer um juízo de residência ao final do mandato, suprimindo assim, de fato, a possibilidade de transmitir o cargo por meio das renúncias. Além disso, ordenou que se estudasse a possibilidade de que as contas do Estado do Brasil fossem fiscalizadas diretamente em Portugal e não pelo provedor das contas, cargo que foi suprimido ${ }^{36}$. Esses movimentos para um maior controle das finanças culminaram na criação da Junta da Fazenda do Brasil em $1612^{37}$.

A partir desse momento, várias nomeações de ofícios incluíam as novas normas. Em 1607, Sebastião Borges foi nomeado provedor da fazenda do Estado do Brasil com 400.000 réis de ordenado, com a ordem do Rei de não "cobrar nem dois nem um por cento nem outros alguns direitos da minha fazenda..." Ademais, a coroa decretava que o cargo devia ocupar-se por cinco anos, acabando assim com a possibilidade de ocupá-lo em propriedade, e que devia ser feita uma "residência" ao final do mandato ${ }^{38}$. Diogo Cirne, nomeado em 1609 provedor da fazenda de Pernambuco, recebeu também a ordem de não obter os dois por cento ${ }^{39}$. Também em 1609 o Rei pediu informações a respeito de os provedores continuarem recebendo "hum ou dous por cento" da fazenda ou os 200.000 réis de ordenado, e procurou saber se Diogo Cirne e Jerônimo de Mendoça tinham cobrado o dois por cento antes de proibição régia ${ }^{40}$. A proibição era difícil de implementar: em 1610, o licenciado Pedro Cascais d'Abreu, provedormor da fazenda do Brasil, fazia uma consulta a El-Rey sobre o fato de os contratadores dos dízimos do açúcar lhe oferecerem uma propina fora do ordenado designado ao cargo ${ }^{41}$. Como já vimos, em 1618, Luís de Sousa informava da cobrança de 2 ou 3 por cento de vários oficiais da fazenda em diferentes capitanias do Brasil.

Como já foi mencionado, para reforçar essa ideia de controle sobre os cargos da monarquia, a coroa pedia limitar o período de uso do ofício, normalmente a 3 anos, depois do qual devia existir uma residência. Essa figura da residência, que já existia previamente no sistema português, mas pouco usada, foi amplamente reforçada durante o período dos Habsburgo, e fundamentalmente nos anos de Filipe III. Em 1605 o rei ordenou a Belchior Damaral que fizesse uma relação das culpas de Francisco de Sousa do tempo em que foi governador do Brasil. Lembrava o rei na ocasião que se devia fazer residência de todos os governadores e capitães de ultramar ${ }^{42}$. Belchior Damaral não pôde completar seu trabalho, pois sabemos que Sebastião Carvalho, que foi ao Brasil em 1607, além de fazer a devassa dos descaminhos do pau-brasil, tinha como uma das suas tarefas realizar a residência de Francisco de Sousa. A instituição da residência provocou grande resistência por parte dos afetados. Em 
1606, o governador de Angola, Manuel Cerveira, evitou que um Felipe Butaca, enviado para efetuar a residência de 3 governadores da capitania africana, realizasse o trabalho encomendado enviando-o de volta para Lisboa com o pretexto de ser "amancebado, mercador e tratante de escravos". O assunto chegou ao Conselho da Índia e ao rei, que decidiram enviar um desembargador junto com o novo governador para tirar a devassa e fazer assim uma boa demonstração de força, para evitar que no futuro os enviados para fazer as residências dos cargos "tivessem medo dos governadores"

Essas ideias para reformar o sistema de provimento de cargos chocavam-se com uma realidade de práticas costumeiras, contradições dentro da própria corte habsbúrguica e atritos no bojo dos conselhos portugueses. Em 1618, em carta ao vice-rei, o rei ordenou que os cargos de capitão na Angola e no Brasil não se deviam prover "na vagante dos providos", como era o normal, mas que se deviam prover em propriedade a pessoas de qualidade. $\mathrm{Na}$ mesma carta, o Rei declarava que não era sua intenção evitar que esses cargos se proviessem em satisfação de serviços pela via do despacho das mercês, e que as capitanias se dessem a pessoas de serviços e merecimentos e em quem concorressem "as mais partes que se requerem para os poderem bem servir" ${ }^{, 44}$. A ordem, aparentemente contraditória daquela outra que pedia prover os cargos por tempo limitado, fazia uma distinção clara entre os cargos da fazenda e outros, como as capitanias, que eram cobiçados pelos membros da nobreza portuguesa.

Outro dos empecilhos para poder implementar as reformas era o contínuo uso das renúncias para a transmissão dos cargos. As Ordenações Filipinas e outras disposições régias legitimavam o uso das renúncias para transmissão dos cargos, contanto que tivessem licença do rei. Havia uma suspeita sobre essas "renunciações". El-Rey advertia em 1603 que era "informado que as renunciações que se fazem de semelhantes ofícios são paleadas" confirmando assim que as renúncias escondiam "interesses ocultos e dinheiros que corriam por baixo de mão", em palavras de Silva ${ }^{45}$. Alguns cargos tornavam-se autênticas dinastias, com vários membros de uma família sucedendo-se no ofício. Por exemplo, o cargo de provedor da fazenda da capitania de Itamaracá passou por renúncia do pai, Afonso Rodrigues Bacellar, ao filho Bento Cabral em 1600, e outro Cabral, Domingos, tinha o cargo em $1617^{46}$. Os Azeredo patrimonializaram também o cargo de provedor da alfândega na capitania do Espírito Santo, criando uma dinastia que perpetuou abusos e práticas ilícitas ${ }^{47}$. Francisco Zorrilla, meirinho do mar e procurador dos índios da Bahia, pediu ao Rei licença para renunciar os cargos na sua filha, Caterina Rios, para a pessoa que com ela casasse. Como não 
obteve resposta régia, decidiu incluir o cargo no testamento, fazendo uso dele como uma propriedade qualquer. Em 1620, Maria Dias, viúva de Francisco Zorrilla, pediu para que a declaração do marido no testamento fosse reconhecida, mas que, enquanto a filha não se casasse, ela pudesse nomear "uma pessoa apta que o sirva [o ofício] para lhe ajudar a alimentar seus filhos" ${ }^{\sharp 8}$. Provavelmente, as intenções de Maria eram vender ou arrendar o cargo para obter um benefício com ele. O assunto chegou ao Conselho da Fazenda que, para dar a licença, pediu que fossem consultadas testemunhas para informar sobre "o valor do ofício e o que renda". Um dos informantes foi o anterior governador do Brasil Gaspar de Sousa, que declarou conhecer os bons serviços de Francisco Zorrilla e que o cargo de meirinho do mar devia render, através dos percalços, uns 300 cruzados. Não se referiu ao valor de compra, mas, no documento da Biblioteca da Ajuda mencionado antes, aparecia como preço do cargo a quantia de 1.000 réis, uma das mais baixas da lista.

Que as renúncias eram utilizadas como escusa para vendas pode-se deduzir de outros dois documentos encontrados no Arquivo de Simancas. Os cargos de porteiro da fazenda, contos e alfândega, guarda dos livros e selador das fazendas e despachos dos navios e certidões de liberdade da Bahia foram outorgados em propriedade a um Antônio Carvalho. Depois da morte deste, a viúva, Maria da Cal, fez o pedido de licença para transmissão dos ofícios à sua filha, para quem casasse com ela. Segundo o testemunho de Maria, o cargo tinha sido outorgado também em serventia a um Francisco de Almeida por 6 anos, com opção a pedir a propriedade do cargo depois do falecimento de Carvalho. Com motivo de uma reclamação feita por "um Luís Cabral", que afirmava ter também direito ao cargo, Almeida viajou ao Reino para litigar pelo oficio. Na ausência de Almeida o cargo passou novamente ao proprietário, Antônio Carvalho. Quando Almeida voltou, depois de ganhar o pleito, constatou que Carvalho estava exercendo as funções que ele tinha em serventia e, para evitar a possível reclamação, Carvalho lhe deu a quantia de 70.000 réis, que era o dote de Maria da Cal. Outras pessoas reclamaram o cargo, junto com Maria e Francisco, mas o Rei decidiu finalmente confirmar a possessão de Maria para a pessoa que casasse com a sua filha, contanto que fosse "português apto e suficiente". $\mathrm{Na}$ ordem régia se mandava também que Francisco Almeida restituísse os 70.000 réis a Maria. Vale também mencionar um outro documento, o pedido de licença para renunciar de um dos criados do bispo Jorge de Ataíde, Gabriel de Correia Bulhões, almoxarife da capitania de Pernambuco, que provocou um conflito entre o rei e o Conselho da Fazenda, quando alguns integrantes deste se opuseram a conceder a tal licença. O almoxarife tinha solicitado a licença para a renúncia em 1618. O Conselho da Fazenda 
remitiu ao rei a aceitação do pedido, mas ordenou que Gabriel apresentasse no Conselho a pessoa na qual faria a renúncia para ver se era apta para o cargo. O Vedor da Fazenda, Conde de Faro, apresentou uma dúvida dizendo que devia avisar ao rei sobre a inconveniência de dar essa licença. Dizia o Conde que a renúncia

"não convém ao serviço de V. Magde e beneficio da sua fazenda por muitas razoes que já se deram que obrigaram a V. Magde a mandar que no estado do Brasil não ouvesse officio da faz ${ }^{\mathrm{a}}$ de propriedade e que neste de Almoxe concorrem mais consideraçoens para não se conceder a tal licença nem dar ocasião a se fazerem vendas de dinheiro" $"$.

A "dúvida" apresentada pelo Vedor da Fazenda foi vista no Conselho e vários dos membros concordaram com o argumento do conde. Na consulta dirigida ao rei pedia-se

\begin{abstract}
"a V. Magde, com a sumissao devida, seja servido mandar ver considerar as razoens que se apontaram na dita Consulta de 17 de maio de 618 que por este dito $\mathrm{Cons}^{\circ}$ se fez sobre esta renunciação: por quanto nas semelhantes há vendas simuladas de dinheiro e principalmente em officios ultramarinos e V. Magde tem mandado que os cargos da Real Faz do Estado do Brasil se não provejam de propriedade tanto que vagarem os que dela estão providos... e não devem servirse de propriedade se não por três anos como ordena o regimento da $\mathrm{Faz}^{\mathrm{a}}{ }^{, 50}$.
\end{abstract}

O Conselho da Fazenda, portanto, não aceitou a resolução inicial da coroa de 29 de agosto de 1618 que dava a licença para a renúncia. Insistia em que o rei devia revisá-la apesar de ter confirmado a tal licença depois da consulta elevada pelo Conselho em maio de $1618^{51}$. A resposta do secretário do rei foi clara: o assunto "não deve tornar a gastar tempo", encerrando assim a questão.

Num outro caso, o Diogo Cirne já citado anteriormente, provedor da fazenda de Pernambuco, pediu licença em 1613 para renunciar ao cargo em Antônio Barreiros, a solicitação foi rechaçada por ir contra o regimento ${ }^{52}$.

Outro costume que pareceu ter uma reprovação real foi o uso indiscriminado dos cargos em propriedade para arrendá-los em serventia a diversas pessoas que às vezes não tinham as "partes" (capacidades) necessárias para o ofício. Foi o caso do cargo de escrivão da alfândega de Salvador da Bahia, que tinha em propriedade Gonçalo de Araújo. Segundo informações fazia 20 anos que dava o cargo em serventia, "por ser tratante e ter engenho", o que provocava que o cargo estivesse ocupado por pessoas que "não servem". O Conselho de Portugal fez proposta em 1602 para embargar o ofício ao tal Gonçalo de Araújo e que fosse outorgado a um peticionário que participou na batalha de Alcacer Quivir, Diogo Baracho ${ }^{53}$.

Se a coroa queria ter um maior controle sobre os provimentos de cargos e as pessoas que os ocupavam, pouco ou nada ajudava o uso indiscriminado que às vezes fazia dos 
mesmos ofícios, que podiam ser outorgados como prêmio para serviços extraordinários em missões organizadas pela coroa, ou também como retribuição para personagens que apareciam pela corte e que ofereciam serviços que o Rei devia recompensar. O monarca nunca deixou de utilizar o provimento de cargos como uma maneira de incentivar iniciativas de conquista ou serviços especiais em guerra ou fazenda. Em 1610, por exemplo, foi concedido a um Pero Lopez Lobo e a um Francisco de Tavarez um alvará de lembrança para "qualquer cargo da fazenda ou justiça que nelle caiba", no primeiro caso para um filho e no segundo para uma filha, que haveria de casar com pessoa apta ${ }^{54}$. O evento da conquista do Maranhão foi uma fonte de petições de cargos e de concessões por parte da coroa para garantir a participação nas campanhas. O suposto inventor do engenho de "palitos", Gaspar Lopes Coelho, foi chamado pelo primeiro governador do Estado do Maranhão, o espanhol Diego de Cárcamo, para acompanhá-lo na viagem que deveria fazer para ocupar o posto no território recentemente conquistado. Cárcamo queria ter alguém com habilidade na construção e administração de engenhos de açúcar. O futuro governador pedia que, como retribuição, Coelho fosse nomeado guarda-mor da imposição dos vinhos e das cargas e descargas de Pernambuco. O governador do Estado do Brasil, Luís de Sousa, declarou que este cargo renderia ao proprietário "quanto quisesse", o qual gerava "insolências e roubos", razão pela qual tinha sido extinguido pela coroa. A recomendação que se fez foi que somente deveria fazer mercê do cargo de guarda-mor da imposição dos vinhos, sem as cargas e descargas, mas mesmo assim o rei negou o pedido e recomendou que apenas lhe fosse outorgada uma sesmaria ou algum cargo no Maranhão ${ }^{55}$. Também para garantir o povoamento da nova conquista maranhense, a coroa ofereceu a Jorge Lemos Betencourt, irlandês que apresentou um projeto para levar 200 casais dos Açores para povoar o Maranhão, uma comenda de 400.000 réis e a capitania de Pernambuco por 4 anos, concedida em carta de 12 de abril de $1617^{56}$. Também em relação com a campanha do Maranhão, Antônio Vicente Cochado, capitão de uma esquadra de sete navios e 600 homens para arrebatar o forte de São Luís aos franceses, recebeu em serventia o cargo de patrão da ribeira e juiz dos calafates de Pernambuco em 1620, quando o cargo já havia sido dado em propriedade a um Manoel Gonçalves Romeu, com a oposição de dois membros do Conselho da Fazenda ${ }^{57}$.

O caso que mais chama a atenção é o do aventureiro e arbitrista inglês Antonio Shirley, que entrou também na lógica das vendas de cargos no Estado do Brasil. Chegou a Madrid em 1606 e estabeleceu boas relações com a coroa, oferecendo seus serviços para armar uma esquadra de navios para limpiar de corsarios el Mediterráneo, nas palavras de 
Bernardo García García ${ }^{58}$. Os serviços de Shirley foram recompensados: em 23 de junho de 1608 lhe foram concedidas as capitanias das fortalezas de Sofala e Ormuz e da "feitoria de Pernambuco", "para as pessoas com que se concertasse", convidando-o assim a vender os cargos. O oferecimento logo se chocou com o Conselho de Portugal que se opôs. Podemos imaginar a resistência portuguesa a que um inglês, que havia estabelecido previamente boas relações com o Xá da Pérsia, pudesse ocupar ou ter a sua disposição a capitania de Hormuz, fortaleza estratégica fundamental no comércio entre o oceano Índico e o Mediterrâneo. Diante da resistência portuguesa, pouco tempo depois da concessão, lhe foi retirado esse privilégio, com uma compensação de 15.000 ducados, para que Shirley pudesse acudir pontualmente "às coisas do real serviço"

A venalidade, portanto, era a principal causa das diferentes "corruptelas" no território da América portuguesa. A sucessão de dinastias em cargos da fazenda e da justiça criava situações de patrimonialização dos cargos que derivavam em abusos. Diferentes trabalhos publicados recentemente, além de outros mais antigos, apontam na direção de uma generalização de práticas fora do controle oficial que fizeram um grande dano à fazenda real $^{60}$. As reformas já comentadas teriam como objetivo acabar com essas práticas, levando à criação em 1612 de uma Junta da Fazenda do Brasil, em cujo alvará se afirmava logo ao início que: "Eu El rey faço saber aos que este alvará virem que eu sou informado que no Estado do Brasil tem havido grande desordem na administração de minha fazenda [...]. ${ }^{61 " ~} \mathrm{~A}$ Junta da Fazenda, através principalmente do trabalho do seu secretário, André Farto da Costa, acabou concluindo que se haviam produzido importantes irregularidades por parte de pessoas que se enriqueceram à custa da Fazenda Real, sendo um deles o governador geral Gaspar de Sousa $^{62}$.

Podemos estabelecer umas conclusões a partir de todos estes casos aqui apresentado: a coroa tentava reformar um sistema no qual as vendas entre particulares eram generalizadas; os comerciantes estavam pagando o salario dos oficiais da monarquia; os "prós e percalços" eram fixados pelos que tinham o ofício sem controle nenhum, além de que ofícios que deviam ser servidos em propriedade estavam sendo ocupados em serventia por questões obscuras como vendas encobertas, e os que estavam em propriedade eram objeto de vendas através de renúncias.

A venalidade era uma prática comum nas primeiras décadas do século XVII na América portuguesa. Havia um mercado generalizado de cargos, no qual estava já estabelecido um preço de compra assim como a quantidade que podia render cada ofício. Esse 
mercado de cargos, salvo exceções, era fundamentalmente um mercado entre particulares, que utilizavam essencialmente o mecanismo da renúncia, mas que incluía também vendas diretas sem licença régia. A coroa estava interessada em controlar este mercado, seja na forma de uma implantação das formas mais rígidas ou "absolutas" da coroa espanhola, denominada por Sérgio Buarque de Holanda "monarquia de El Escorial”, sobre as estruturas mais flexíveis do sistema português, seja como um aspecto a mais de um movimento reformista que estava operando nos territórios portugueses de ultramar e no próprio Portugal peninsular. As autoridades de Madri tentaram limitar alguns dos excessos, suprimindo alguns cargos, eliminando o pagamento do dois por cento dos arrendatários dos impostos aos oficiais régios, proibindo a obtenção de cargos da fazenda em propriedade, evitando que pudessem ser transmitidos por meio de renúncias, e quando existiam essas renúncias, que fossem feitas em pessoas aptas para o cargo. A errática política de provimento de cargos e as contradições e disputas existentes entre diferentes órgãos centrais da monarquia, fundamentalmente entre as autoridades de Madri e os conselhos portugueses, configuraram um sistema desorganizado e caótico, no qual as reformas foram adiadas ou não implementadas, situação que chegaria ao momento crítico das conquistas holandesas. O fracasso das reformas seria assim outra das causas da crise total do sistema dos Habsburgo nos territórios portugueses atlânticos.

Não podemos pensar nas monarquias do Antigo Regime sob a óptica da racionalidade dos estados contemporâneos. Uma política reformista era mais um projeto que se chocava com uma realidade complexa do que um plano detalhado e organizado para uma transformação radical das estruturas administrativas. Entraves políticos, econômicos, sociais e de mentalidades evitavam uma implementação global das reformas, contribuindo finalmente ao caos burocrático que caracterizava a realidade política da Idade Moderna.

\section{Notas}

\footnotetext{
${ }^{1}$ A pesquisa realizada para este texto tem sido financiada pelo projeto "Circulación de personas, libros, objetos y noticias entre Brasil y los territorios de la Monarquía Hispánica (1580-1668)", HAR2016-78099-P do Ministério de Economia e Competitividade da Espanha (MINECO).

${ }^{2}$ Biblioteca Nacional de Madrid, (BN), Ms. 3015, "Relaçao de todos os oficios da fazenda e justisa que ha neste Estado do Brazil, e quaes pertencen ao provimento de V. Mag. e aos dos donatarios em vida, ou por tempo limitado, para cuja inteligencia se hao de supor os premissos segintes:" fols. 15-32.

${ }^{3} \mathrm{O}$ ordenado era o salário pago a um oficial, conforme o regimento do ofício. Os percalços eram ingressos que eram obtidos fora do ordenado, na prática diária do ofício.

${ }^{4}$ MARQUES, Guida. De um governo ultramarino. A institucionalização da América Portuguesa no tempo da União das Coroas (1580-1640). In: CARDIM, Pedro; COSTA, Leonor Freire; CUNHA, Mafalda Soares da (orgs.) Portugal na Monarquia Hispânica: dinâmicas de integração e de conflito. Lisboa: Centro de História de Além-Mar, 2013, p. 235.
} 
${ }^{5}$ BN, Ms. 3015, "Relaçao de todos os oficios da fazenda e justisa que ha neste Estado do Brazil, e quaes pertencen ao provimento de V. Mag. e aos dos donatarios em vida, ou por tempo limitado, para cuja inteligencia se hao de supor os premissos segintes:", fol. 15v. O grifo é nosso.

${ }^{6}$ Biblioteca da Ajuda, Lisboa (BA), Cod. 51-VI-54, 2 de outubro de 1606: "Relação dos officios dapresentação de S. Magde da Justiça e fazenda e o que valem de renda e de compra em vida...”, fols. 160-166v. e 229-235.

${ }^{7}$ BN, Ms. 3015, "Relaçao de todos os oficios da fazenda e justisa que ha neste Estado do Brazil, e quaes pertencen ao provimento de V. Mag. e aos dos donatarios em vida, ou por tempo limitado, para cuja inteligencia se hao de supor os premissos segintes:", fols. 16-17r.

${ }^{8}$ Archivo General de Simancas (AGS), Secretarías Provinciales (SSPP), libro 1575. Relación de Gastos Coloniales, publicado por MELLO, José Antonio Gonsalves de (ed.). Relação de Ambrósio de Siqueira (1605) da receita e despesa do Estado do Brasil. Separata da Revista do Instituto Arqueológico, Histórico e Geográfico Pernambucano, v. 49. Recife: Instituto Arqueológico, Histórico e Geográfico Pernambucano, 1977, p. 125.

${ }^{9}$ Ibidem, p. 127.

${ }^{10}$ ROMEIRO, Adriana. Corrupção e poder no Brasil: uma história, séculos XVI a XVIII. Belo Horizonte: Autêntica, 2017, p. 33.

${ }^{11}$ PIETSCHMANN, Horst. Burocracia y corrupción en Hispanoamérica colonial. Una aproximación tentativa. Nova Americana, Torino, 1982, pp. 11-37.

${ }^{12}$ ANDÚJAR CASTILLO, Francisco; PONCE LEIVA, Pilar (cords.). Debates sobre la corrupción en el mundo ibérico, siglos XVI-XVIII. Alicante: Biblioteca Virtual Miguel de Cervantes, 2018, pp. 11-12.

${ }^{13}$ HESPANHA, Antônio Manuel. Por que é que foi "portuguesa" a expansão portuguesa? In: SOUZA, Laura de Mello e; FURTADO, Júnia Ferreira; BICALHO, Maria Fernanda (Org.). O governo dos povos. São Paulo: Alameda, 2009, p. 46, apud ROMEIRO, Adriana, Corrupção e poder... op. cit., p. 42.

${ }^{14}$ ROMEIRO, ibidem, p. 49.

15 Ibid., p. 89.

${ }^{16}$ BERTRAND, Michel. Poder peleado, poder compartido: familias y estado en la América española colonial. In MOLINA PUCHE, Sebastián; IRIGOYEN LÓPEZ, Antonio (eds.). Territorios distantes, comportamientos similares. Murcia, Universidad de Murcia, 2009.

${ }^{17}$ STUMPF, Roberta; CHATURVEDULA, Nandini (Orgs.). Cargos e ofícios nas monarquias ibéricas: provimento, controlo e venalidade (séculos XVII-XVIII). Lisboa: CHAM, 2012; nesta mesma obra o texto de STUMPF, Roberta. Formas de venalidade de ofícios na monarquia portuguesa do século XVIII, pp. 279-298; STUMPF, Roberta. Venalidad de oficios en la monarquía portuguesa: un balance preliminar. In: ANDÚJAR CASTILLO, Francisco; FELICES DE LA FUENTE, María del Mar (Eds.). El poder del dinero. Ventas de cargos y honores en el Antiguo Régimen. Madrid: Biblioteca Nueva, 2011, pp. 331-344; SILVA, Francisco R. da. Venalidade e hereditariedade dos ofícios públicos em Portugal nos séculos XVI e XVII. Alguns aspectos. Revista de História, 8, 1988, págs. 203-213; OLIVAL, Fernanda. Economía de la merced y venalidad en Portugal (siglos XVII y XVIII). In: ANDÚJAR CASTILLO, Francisco; FELICES DE LA FUENTE, María del Mar (Eds.). El poder del dinero... pp. 345-357; GALLO, Alberto. La venalidad de oficios públicos en Brasil durante el siglo XVIII. In BELLINGERI, Marco (Cord.). Dinámicas de Antiguo Régimen y orden constitucional. Representación justicia y administración. Siglos XVIII, XIX. Torino: Otto, 2000, pp. 97-175.

${ }^{18}$ STUMPF, Roberta. Formas de venalidade de ofícios na monarquia portuguesa do século XVIII. In: STUMPF, Roberta; CHATURVEDULA, Nandini (orgs.). Cargos e ofícios nas monarquias ibéricas: provimento, controlo e venalidade (séculos XVII-XVIII). Lisboa: CHAM, 2012, pp. 284-285.

${ }^{19}$ STUMPF, Roberta. Venalidad de oficios en la monarquia portuguesa... op. cit. p. 335, que cita o Memorial de Pero Soiz Soares. In: MARQUES, João. A parenética portuguesa e a dominação filipina, Porto, Ed. Porto e INIC, 1986, p. 140.

${ }^{20}$ SILVA, Francisco R. da. Venalidade e hereditariedade dos ofícios públicos em Portugal nos séculos XVI e XVII. Alguns aspectos, op. cit. págs. 203-213.

${ }^{21}$ Este argumento não parece ter relação com uma maior ou menor moral ou ética dentro da corte, mas com o perigo de mudar a relação de forças no sistema burocrático português entre a nobreza e os poderosos comerciantes sem títulos que queriam entrar na administração para conseguir, por meio dela, um status social nobre, ou diretamente um título de nobreza, o que talvez podia ser um dos impedimentos para uma generalização das vendas, questão esta que não podemos comprovar com a informação disponível.

${ }^{22}$ Ibidem, págs. 210-211 e 213.

${ }^{23}$ STUMPF, Roberta. Os provimentos de ofícios: a questão da propriedade no Antigo Regime português, Topoi. Rio de Janeiro, v. 15, n. 29, jul./dez. 2014, pp. 612-634, p. 625.

${ }^{24}$ CHATURVEDULA, Nandini. Entre particulares: venalidade na Índia portuguesa no século XVII. In STUMPF, Roberta; CHATURVEDULA, Nandini (Orgs.). Cargos e ofícios nas monarquias ibéricas: provimento, controlo e venalidade (séculos XVII-XVIII). Lisboa: CHAM, 2012, pp. 267-278. 
${ }^{25}$ Apud CARRARA, Ângelo Alves. Costos y beneficios de una colonia: introducción a la fiscalidad colonial del Estado de Brasil, 1607-1808. Investigaciones de Historia Económica, IHE, fevereiro, 2010, pp. 13-42., p. 14.

${ }^{26}$ Ibidem, p. 21.

${ }^{27}$ Arquivo Nacional da Torre do Tombo (ANTT), Convento da Graça de Lisboa, Tomo VI F, fols. 147 e ss., "Prouincia do Brasil" e Biblioteca da Ajuda (BA), Cod. 51-IX-25, fls. 132-142v., "Relação das Capitanias do Brasil", s. f., publicado em MATOS, Artur Teodoro de. O império colonial português no início do século XVII: elementos para um estudo comparativo das suas estruturas económicas e administrativas. ARQUIPÉLAGO. História, $2^{\mathrm{a}}$ série, vol. 1, $\mathrm{n}^{\mathrm{o}}$ 1, 1995, pp. 181-223. FALCÃO, Luis de Figueiredo. Livro em que se contém toda a fazenda e real patrimônio dos reinos de Portugal, Índia e ilhas adjacentes. Lisboa: Imprensa Nacional, 1859, [Madrid, 1607].

${ }^{28}$ BA, Cod. 51-VI-54, 2 de octubre de 1606: "Relação dos officios dapresentação de S. Magde da Justiça e fazenda e o que valem de venda e de compra em vida...", fols. 160-166v. y 229-235.

${ }^{29}$ A transcrição completa do documento em: SANTOS PÉREZ, José Manuel. Visita, residência, venalidade. As "práticas castelhanas" no Brasil de Filipe III. In: MEGIANI, Ana Paula; SANTOS PÉREZ, José Manuel; SILVA, Kalina Vanderlei (orgs.). O Brasil na Monarquia Hispânica. Novas interpretações. São Paulo: Humanitas, 2015, pp. 23-37.

${ }^{30}$ MARQUES, Guida. O Estado do Brasil na União Ibérica. Dinâmicas políticas no Brasil no tempo de Filipe II de Portugal. Penélope, núm. 27. Lisboa: Cooperativa Penélope, Fazer e Desfazer a História 2002, pp. 7-35.

${ }^{31}$ AGS, SP, libro 1516, fol. 65v., 23 de mayo de 1618.

${ }^{32}$ SANTOS PÉREZ, José Manuel. La conquista y colonización de Maranhão-Grão Pará: el gran proyecto de la Monarquía Hispánica para la Amazonia brasileña (1580-1640). Revista de Estudios Brasileños, volume 6, nº 11, 2019. Sobre todas essas transformações vide MARQUES, Guida. De um governo ultramarino. A institucionalização da América Portuguesa no tempo da União das Coroas (1580-1640), op. cit.

${ }^{33}$ Banco de dados "Brasilhis", http://brasilhis.usal.es. Acesso em 11 de março de 2019.

${ }^{34}$ AGS, SP, Libro 1491, fol. 71, 7 de dezembro de 1604, Carta ao vice-rei.

${ }^{35}$ BA, Cod. 51-VII-15, fol. 54.

${ }^{36}$ BA, Cod 51-VII-15, 30 de diciembre de 1606, "Carta de S. Magde ao Conselho da Índia".

${ }^{37}$ MARQUES, Guida. O Estado do Brasil na União Ibérica. Op. cit. p. 11.

${ }^{38}$ BA, Cod. 51-VII-15, fol. 170 (148 antigo).

${ }^{39}$ AGS, SSPP, libro 1498, fol. 41 v. Carta do rei ao vice-rei, 25 de fevereiro de 1609.

${ }^{40}$ AGS, SSPP, libro 1500, fol. 66 v. Sobre o officio de Provedor mor do Brasil, 30 de junho de 1609.

${ }^{41}$ AGS, SSPP, libro 1503, fol. 11, Sobre uma consulta do gobernador do Brasil e outra do licenciado $\mathrm{P}^{\mathrm{o}}$ de Casquaes d'Abreu, 14 de junho de 1610.

${ }^{42}$ AGS, SSPP, libro 1491, fol. 225, El rei ao vice-rei, 26 de agosto de 1605.

${ }^{43}$ AGS, SSPP, libro 1476, fols. 174 e ss. Conselho de Portugal ao rei, 16 de outubro de 1606.

${ }^{44}$ AGS, SSPP, libro 1516, fol. 63, Carta do rei ao vice-rei, 23 de mayo de 1618.

${ }^{45}$ SILVA, Francisco R. da. Op. cit. p. 207.

${ }^{46}$ ANTT, Chancelaria de D. Filipe II, 21.02.1600, Alvará de Provedor da Fazenda da Capitania de Itamaracá a Bento Cabral. "Domingos Cabral", entrada do Banco de Dados "Brasilhis", http://brasilhis.usal.es/es/personaje/domingos-cabral. Acesso em 24 de fevereiro de 2019.

${ }^{47}$ FERNANDES, Anna Karoline da Silva. A administração espanhola no Espírito Santo durante a monarquia dual (1580-1640). Dissertação de Mestrado em História, Universidade Federal do Espírito Santo, Vitória, 2017.

${ }^{48}$ AGS, SSPP, libro 1473, fol. 260-262, 11 de septiembre de 1609, "Sobre Maria Dias Veuva de Frco. Zorrilha que foy meyr ${ }^{\circ}$ do mar da Bahia de todos os Santos ptes do Brasil".

${ }^{49}$ AGS, SSPP, libro 1474, fol. 389, Duvida do conde de Faro sobre a petição de licença de Gabriel de Bulhões, 15 de mayo de 1620.

${ }^{50}$ AGS, SSPP, libro 1474, fols. 387 a 388v. Consulta de uma petição de Gabriel de Correa de Bulhões, almoxarife da capitania de Pernambuco. 9 de junho de 1620. O sublinhado é nosso.

${ }^{51}$ A licença em AGS, SSPP, libro 1516, fol. 113v., Autorização para Gabriel Correia de Bulhões almoxarife da Fazenda da capitania de Pernambuco, poder renunciar ao dito oficio. 29 de agosto de 1618.

${ }_{52}$ AGS, SSPP, libro 1508, fol. 31, Sobre a petição de Diogo Cirne, provedor da Fazenda na capitania de Pernambuco que pretendia renunciar a seu cargo, 30 de maio de 1613.

${ }^{53}$ AGS, SSPP, libro 1462, fol. 64, Conselho de Portugal, Diogo Baracho, 17 de abril de 1602.

${ }^{54}$ AGS, SSPP, libro 1498, fol. 78 v., Mercês concedidas por Sua Magestade a Pero Loes Lobo, do hábito de Cristo e uma tença e a Francisco Tavarez, de um alvará de lembrança. 23 de março de 1610.

${ }^{55}$ AGS, SSPP, libro 1473, fol. 362, "Consulta sobre uma petição de Gaspar Lopes Coelho e informações pedidas por El-Rey ao governador do Brasil D. Luís de Souza”, 10 de noviembre de 1620.

${ }^{56}$ AGS, SSPP, libro 1474, fol. 413. 
${ }^{57}$ AGS, SSPP, libro 1474, fols. 478-479, 29 de junho de 1620.

${ }^{58}$ GARCÍA GARCÍA, Bernardo. La Pax hispánica. Política exterior del Duque de Lerma. Lovaina: Leuven University Press, 1996, p. 178.

${ }^{59}$ AGS, SSPP, libro 1499, fol. 31v. (sd, 1608). García García, Bernardo, La Pax hispánica. Política exterior del Duque de Lerma, Lovaina: Leuven University Press, 1996, pp. 178-179.

${ }^{60}$ FERNANDES, Anna Karoline da Silva. A administração espanhola no Espírito Santo durante a monarquia dual. Op. cit..; SÁ, Helena de Cassia Trindade de. A alfândega do Rio de Janeiro: da União Ibérica ao fim da Guerra da Restauração (ca.1580- ca.1668). Dissertação de mestrado em História, Universidade Federal do Estado do Rio de Janeiro, Rio de Janeiro, 2016; MARQUES, Guida. De um governo ultramarino. Op. cit.; COSTA, Cleonir Xavier de Albuquerque da Graça e. Receita e despesa do Estado do Brasil no periodo filipino. Dissertação de mestrado, UFPE, Recife, 1985.

${ }^{61}$ Apud, FERNANDES, Anna Karoline da Silva. A administração espanhola no Espírito Santo durante a monarquia dual (1580-1640). Op. cit. p. 73.

${ }^{62}$ COSTA, Cleonir Xavier de Albuquerque da Graça e. Receita e despesa do Estado do Brasil no periodo filipino. Dissertação de mestrado, UFPE, Recife, 1985. p. 29. MARQUES, Guida. O Estado do Brasil na União Ibérica. Dinâmicas políticas no Brasil no tempo de Filipe II de Portugal, op. cit., p. 12. 